\title{
The effects of chronic L-arginine treatment on vascular responsiveness of streptozotocin-diabetic rats
}

\author{
A. Tanju Özçelikay*, Aydın Tay, Deniz Dinçer, Suna Meral, \\ Nuray Yıldızoğlu-Arı, V. Melih Altan \\ Department of Pharmacology, Faculty of Pharmacy, Ankara University, 06100 Tandoğan, Ankara, Turkey \\ Received 8 March 1999; accepted 8 March 1999
}

\begin{abstract}
In this study, the protective effects of L-arginine treatment in vivo on vascular reactivity of streptozotocin (STZ)-induced 12week-old diabetic rats were examined. Loss of weight, polydipsia, polyphagia, hyperglycemia, hypoinsulinemia, and elevated levels of plasma cholesterol and triglyceride were observed in diabetic rats. L-arginine treatment $(1 \mathrm{mg} / \mathrm{mL}$ in drinking water) did not significantly affect these metabolic and biochemical abnormalities. Plasma malondialdehyde (MDA) levels in untreated diabetic rats were also significantly higher than untreated controls. However, L-arginine treatment prevented the increase in MDA level of plasma of diabetic rats. Contractile responses, but not sensitivity to noradrenaline (NA), were significantly increased in diabetic rats compared to controls. Treatment of diabetic rats with L-arginine completely prevented the increase in NA responses. Relaxation response to acetylcholine (ACh), but not to sodium nitroprusside (SNP), in diabetic aorta has been found to be significantly decreased as compared with controls. However, there were no significant differences in $\mathrm{pD}_{2}$ values of acetylcholine in either of the groups. L-arginine treatment increased the ACh responses to the control level. All effects of L-arginine on vascular reactivity were found to be specific for diabetic rats and not controls. These results suggest that functional abnormalities occurred in aorta from diabetic rat might at least in part result from L-arginine deficiency, and the lipid peroxidation-lowering effect of L-arginine may account for its protective effect on vascular reactivity of diabetic rats. (c) 1999 Elsevier Science Inc. All rights reserved.
\end{abstract}

Keywords: L-arginine treatment; Diabetic rat; Aorta; Lipid peroxidation

\section{Introduction}

Mortality from cardiovascular disease, including hypertension, atherosclerosis, microangiopathy, and congestive heart failure, is almost three times higher in the diabetic population than in the general population (Garcia et al., 1974; Jarrett, 1989). Although the aetiology of vascular disorders in diabetes is not completely understood, it has been suggested that alterations in the reactivity of blood vessels to neurotransmitters and circulating hormones are responsible for the functional abnormalities of blood vessels in diabetes (Christlieb et al., 1976; Weidmann et al., 1985). Although there are conflicting results, in a great number of the previous studies, increased vascular responsiveness to contractile agents, such as noradrenaline (NA) in streptozotocin

* Corresponding author. Tel.: +90-312-212-6805, ext. 206; fax: +90-312-213-1081.

E-mail address: ozcelika@pharmacy.ankara.edu.tr (A.T. Özçelikay)
(STZ)-diabetic rats, has been obtained (Macleod, 1985; Harris and Macleod, 1988; Abebe et al., 1990). On the other hand, there is good evidence that endotheliumdependent relaxation is impaired in diabetic patients (McVeigh et al., 1992; McNally et al., 1994) as well as STZ-diabetic rats (Oyama et al., 1986; Kamata et al., 1989). Oxidative stress is believed to be major factor in the development of vascular complications associated with diabetes mellitus (Baynes, 1992; Cohen 1993; Tesfamariam, 1994; Giuglino et al., 1995). Chang et al. (1993) reported that increased maximal response to vasoconstricting agents was due to a deficiency in endothelium-dependent relaxation and increased NAinduced phosphoinositide turnover in aortas from diabetic rats, and that both the decreased endothelial activity and the augmented contractility resulted from increased oxidative stress in STZ-diabetic rats. Another possible mechanism involved in abnormal endotheliumdependent relaxation in diabetes may be decreased levels of arginine in plasma and vascular tissue. Indeed, 
plasma levels of arginine have been found to be reduced in diabetic patients (Hagenfeldt et al., 1989; Grill et al., 1992) and in STZ-diabetic rats (Pieper and Peltier, 1995; Pieper et al., 1996; Pieper and Dondlinger, 1997). In addition, Pieper and Dondlinger (1997) have found that vascular tissue arginine is also decreased in STZdiabetic rats. L-arginine incubation in organ bath restores relaxation responses to ACh in aorta from STZ (Pieper and Peltier, 1995; Pieper and Dondlinger, 1997) or BB-diabetic (Pieper et al., 1997) rats, but it has no effect on control aorta. Pieper et al. (1996) has also shown that short-term (3 days) supplement of L-arginine in drinking water 8 weeks after induction of diabetes completely reverses defective endothelium-dependent relaxation and restores the decreased cGMP production stimulated by ACh in untreated diabetic rats to control levels. On the other hand, there are several reports showing that L-arginine can reduce lipid peroxidation (Xiong et al., 1994; Wascher et al., 1997; Lubec et al., 1995, 1997a, 1997b), which is associated with increased oxidative stress. Among these studies, it has been found that L-arginine reduces lipid peroxidation in diabetic patients (Lubec et al., 1997a) and diabetic kk mouse (Lubec et al., 1997b). To our knowledge, however, there is no data concerning the effect of long-term $\mathrm{L}$-arginine treatment on vascular reactivity and on lipid peroxidation in STZ-diabetic rats. Therefore, in this study, we evaluated the effects of chronic L-arginine treatment on the vascular reactivity in diabetic aorta. Furthermore, we also examined whether L-arginine treatment affects some metabolic and biochemical parameters-including plasma levels of malondialdehyde (MDA), a marker of lipid peroxidation-in diabetic and control rats.

\section{Materials and methods}

\subsection{Animals}

Inbred male Wistar rats procured locally (body weight 170-220 g, 8-10 weeks old) were used in the present study. The animals were housed in individual cages at a constant temperature $\left(22^{\circ} \mathrm{C}\right)$ with a fixed 12:12-h light-dark cycle (lights on 0700-1900). This study was approved by the Ethics Committee of the Faculty of Veterinary Medicine, University of Ankara.

The animals were divided into four experimental groups: untreated control $(\mathrm{n}=9)$, L-arginine treated control $(\mathrm{n}=11)$, untreated diabetic $(\mathrm{n}=11)$, and L-arginine-treated diabetic $(\mathrm{n}=11)$. Diabetes was induced by a single tail vein injection of STZ $(50 \mathrm{mg} / \mathrm{kg})$. STZ was dissolved in $1 \mathrm{ml}$ of cold citrate buffer $(0.1 \mathrm{M}$, $\mathrm{pH}$ 4.5) immediately before use. Control animals received the citrate buffer solution alone. Seven days after STZ injection, blood glucose levels were determined using an Ames glucometer (Glucometer III,
Bayer Diagnostics, Puteaux, France) and blood glucose test strips (Glucofilm, Bayer Diagnostics, Germany). Rats with blood glucose levels of $16.7 \mathrm{mM}$ or above were considered to be diabetic.

\subsection{L-arginine treatment}

One week after STZ injection, L-arginine-treated diabetic and control rats were given drinking solutions (distilled water) containing L-arginine at $1 \mathrm{mg} / \mathrm{ml}$ concentration. Untreated control and diabetic rats received distilled water alone. All rats were maintained for 12 weeks with free access to food and water. Average food and fluid intake were recorded twice per week.

\subsection{Isolation of aortic rings}

Twelve weeks after the induction of diabetes, the rats were anesthetized with $60 \mathrm{mg} / \mathrm{kg}$ thiopental sodium (i.p.). After opening the abdomen, blood samples (3-5 $\mathrm{ml}$ ) were taken from renal arteries, placed in heparinized tubes, and centrifuged at $3.000 \mathrm{~g}$ for $20 \mathrm{~min}$. The plasma samples were stored in $-30^{\circ} \mathrm{C}$ for determination of final glucose, insulin, triglyceride, and cholesterol measurements.

Descending thoracic aortas were carefully excised and placed in cold physiological saline solution (PSS) containing $(\mathrm{mM})$ : $118 \mathrm{NaCl}, 4.7 \mathrm{KCl}, 2.5 \mathrm{CaCl}_{2}, 1.2$ $\mathrm{MgSO}_{4}, 1.2 \mathrm{KH}_{2} \mathrm{PO}_{4}, 25 \mathrm{NaHCO}_{3}$, and 11.1 glucose. The aortas were cleaned of excess connective tissue and fat and cut into rings of approximately $3-5 \mathrm{~mm}$ in length. In all experiments, special care was taken to avoid damaging the luminal surface of endothelium. Aortic rings were suspended in 20-ml jacketed organ baths filled with $20 \mathrm{ml}$ of PSS continuously aerated with a mixture of $5 \% \mathrm{CO}_{2}, 95 \% \mathrm{O}_{2}, \mathrm{pH} 7.4$, at $37^{\circ} \mathrm{C}$. One end of the aortic rings was connected to a tissue holder and the other to an isometric force transducer (No. 7004, Ugo Basile, Varese, Italy) connected to a microdynamometer (Unirecord, Ugo Basile). The rings were equilibrated for $60 \mathrm{~min}$ under a resting tension of $2 \mathrm{~g}$ before experiments were begun. During equilibration period, the rings were washed every $15 \mathrm{~min}$. All experiments were done in the presence of $1 \mu \mathrm{M}$ timolol, $1 \mu \mathrm{M}$ imipramine, and $1 \mu \mathrm{M}$ prednisolone to eliminate the effects of $\beta$-adrenoceptors, neuronal uptake, and extraneuronal uptake, respectively.

\subsection{Experimental procedure}

At the end of the equilibration period, a cumulative concentration-response curve for NA $\left(10^{-8}-3 \times 10^{-5}\right.$ $\mathrm{mol} / \mathrm{L}$ ) was carried out. After rinsing with PSS to baseline tension, rings were equilibrated for $30 \mathrm{~min}$. The rings were then contracted with a submaximal concentration of NA, which produced $70-80 \%$ of maximal response. The NA concentration was usually $1 \mu \mathrm{mol} / \mathrm{L}$ but was varied between $3 \times 10^{-7}-3 \times 10^{-6} \mathrm{~mol} / \mathrm{L}$ to obtain equieffective agonist activity. After reaching 
the plateau of contraction, cumulative concentrationresponse curves to ACh $\left(10^{-8}-3 \times 10^{-5} \mathrm{~mol} / \mathrm{L}\right)$ and sodium nitroprusside (SNP; $10^{-11}-10^{-6} \mathrm{~mol} / \mathrm{L}$ ) were obtained to evaluate endothelium-dependent and -independent relaxations, respectively.

After each experiment, aortic rings were dried at $50^{\circ} \mathrm{C}$ for $5 \mathrm{~min}$, weighed, and measured, and the crosssectional area (csa) was calculated using the following formula: Cross-sectional area $\left(\mathrm{mm}^{2}\right)=$ weight $(\mathrm{mg}) \times$ $[\text { length }(\mathrm{mm}) \times \text { density }]^{-1}$. The density of the preparations was assumed to be $1.05 \mathrm{mg} / \mathrm{mm}^{3}$ (Abebe et al., 1990).

\subsection{Biochemical measurements}

Plasma insulin levels were measured by standard radioimmunoassay techniques using a commercial kit available from DPC (Diagnostic Products Corporation, Los Angeles, CA). Final plasma glucose levels were determined by the glucose oxidation method using a glucose kit (Glukofix, Menarini Diagnostics, Florence, Italy). Menarini Diagnostics kits were also used to measure the levels of cholesterol and triglyceride in the plasma. The cholesterol and triglyceride levels were determined using enzymatic and colorimetric methods on a programmable photometer (Fototron, Diatron, Wien, Austria). Plasma levels of MDA, one of the end products of lipid peroxidation, were determined by the thiobarbituric acid (TBA) reaction according to a slightly modified Satoh (1978) method. To $0.5 \mathrm{~mL}$ plasma, 2.5 $\mathrm{mL} 20 \%$ trichloroacetic acid (TCA) and $0.025 \mathrm{~mL}$ butylated hydroxy-toluene (BHT; $88 \mathrm{mg} / 10 \mathrm{~mL}$ absolute alcohol) were added, and then the tubes were left to stand for $10 \mathrm{~min}$ at room temperature. After centrifugation, the supernatant was decanted, and the precipitate was washed with sulfuric acid $(0.05 \mathrm{~mol} / \mathrm{L})$ twice. Then the sulfuric acid and $0.2 \%$ TBA prepared in $2 \mathrm{~mol} / \mathrm{L}$ sodium sulphate were added to this precipitate and heated for $30 \mathrm{~min}$ in a boiling water bath. After cooling, n-butanol was added, the tubes were vortexed and centrifuged, and absorbance of the organic phase was read at $530 \mathrm{~nm}$.

\subsection{Drugs}

Streptozotocin, (-) noradrenaline bitartrate, L-arginine hydrochloride, acetylcholine chloride, sodium nitroprusside, timolol maleate, imipramine hydrochloride, BHT, and TBA were purchased from Sigma (St. Louis, MO). Noradrenaline was dissolved in distilled water containing $1 \mathrm{mg} / \mathrm{ml}$ ascorbic acid to prevent oxidation of the drug. Thiopental sodium and prednisolon were obtained from Abbott and Fako (Istanbul, Turkey) respectively.

\subsection{Data and statistical analysis}

Results are expressed as the mean \pm SEM. Contractile responses to NA are expressed in tension $(\mathrm{g})$ in response to the agonist per cross-sectional area of aorta $\left(\mathrm{mm}^{2}\right)$. Relaxation responses of ACh and SNP are expressed as a percentage decrease of the maximum contractile response. The sensitivity to the agonists is evaluated as the $\mathrm{pD}_{2}$, which is the negative logarithm of the concentration of the drug required to produce $50 \%$ of maximum response. $\mathrm{EC}_{50}$ values were calculated using non-linear regression analysis. Statistical analysis was carried out using one-way analysis of variance followed by Neuman-Keul's test. Results were considered significantly different if $\mathrm{p}<0.05$.

\section{Results}

At the end of 12 weeks, the body weight of the untreated diabetic rats was found to be significantly decreased compared with control rats (Table 1). Untreated diabetic rats also had elevated food and fluid intakes over those of control rats (Table 1). Treatment of diabetic rats with $\mathrm{L}$-arginine did not cause any change in the above parameters of untreated diabetic rats (Table 1). Similarly, L-arginine treatment did not significantly alter food and fluid intake and weight gain of control rats. In addition, no significant change was found between the cross-sectional areas of all experimental groups (Table 1).

Untreated and L-arginine-treated diabetic rats also

Table 1

Body weights, fluid intakes, food intakes, and cross-sectional areas (csa) of untreated control,

L-arginine-treated control, untreated diabetic, and L-arginine-treated diabetic rats

\begin{tabular}{lcccc}
\hline & $\begin{array}{l}\text { Body weight } \\
(\mathrm{g})\end{array}$ & $\begin{array}{l}\text { Fluid intake } \\
(\mathrm{ml} / \text { day })\end{array}$ & $\begin{array}{l}\text { Food intake } \\
(\mathrm{g} / \mathrm{day})\end{array}$ & $\begin{array}{l}\text { csa } \\
\left(\mathrm{mm}^{2}\right)\end{array}$ \\
\hline $\begin{array}{l}\text { Control rats } \\
\quad \text { Untreated }\end{array}$ & $357.8 \pm 10.1$ & $37.1 \pm 0.5$ & $26.2 \pm 0.6$ & $0.77 \pm 0.08$ \\
$\quad \begin{array}{l}\text { L-arginine-treated } \\
\text { Diabetic rats }\end{array}$ & $352.4 \pm 10.7$ & $37.5 \pm 1.2$ & $24.9 \pm 0.3$ & $0.79 \pm 0.07$ \\
$\quad$ Untreated & $215.6 \pm 8.4^{*}$ & $162.4 \pm 1.6^{*}$ & $37.3 \pm 0.5^{*}$ & $0.56 \pm 0.04$ \\
$\quad$ L-arginine-treated & $205.4 \pm 9.2^{*}$ & $165.7 \pm 1.5^{*}$ & $37.6 \pm 0.4^{*}$ & $0.69 \pm 0.06$ \\
\hline
\end{tabular}

* Significantly different from untreated and L-arginine-treated control groups $(\mathrm{p}<0.05)$.

Values are mean \pm SEM of $7-11$ observations in each group. 
Table 2

Plasma glucose, insulin, cholesterol, triglyceride, and MDA levels of untreated control, L-arginine-treated control, untreated diabetic, and L-arginine-treated diabetic rats

\begin{tabular}{lccccc}
\hline & $\begin{array}{l}\text { Plasma } \\
\text { glucose } \\
(\mathrm{mmol} / \mathrm{L})\end{array}$ & $\begin{array}{l}\text { Plasma } \\
\text { insulin } \\
(\mathrm{pmol} / \mathrm{L})\end{array}$ & $\begin{array}{l}\text { Plasma } \\
\text { cholesterol } \\
(\mathrm{mmol} / \mathrm{L})\end{array}$ & $\begin{array}{l}\text { Plasma } \\
\text { triglycerides } \\
(\mathrm{mmol} / \mathrm{L})\end{array}$ & $\begin{array}{l}\text { Plasma } \\
\mathrm{MDA} \\
(\mu \mathrm{mol} / \mathrm{L})\end{array}$ \\
\hline $\begin{array}{l}\text { Control rats } \\
\quad \text { Untreated }\end{array}$ & $5.8 \pm 0.2$ & $180 \pm 28$ & $1.49 \pm 0.09$ & $1.05 \pm 0.04$ & $3.74 \pm 0.05$ \\
$\quad \begin{array}{l}\text { L-arginine-treated } \\
\text { Diabetic rats }\end{array}$ & $5.9 \pm 0.3$ & $172 \pm 14$ & $1.50 \pm 0.11$ & $1.13 \pm 0.07$ & $3.66 \pm 0.14$ \\
$\quad \begin{array}{l}\text { Untreated } \\
\text { L-arginine-treated }\end{array}$ & $21.0 \pm 0.5^{*}$ & $32 \pm 5^{*}$ & $1.99 \pm 0.25^{*}$ & $1.97 \pm 0.22^{*}$ & $5.13 \pm 0.13^{* *}$ \\
\hline
\end{tabular}

* Significantly different from untreated and L-arginine-treated control groups $(\mathrm{p}<0.05)$.

** Significantly different from all other groups $(\mathrm{p}<0.05)$.

Values are mean \pm SEM of $7-11$ observations in each group.

exhibited significantly elevated plasma glucose, cholesterol, and triglycerides but decreased insulin levels relative to both untreated and L-arginine-treated controls. (Table 2). Plasma MDA levels of untreated diabetic rats were significantly higher than untreated controls. While L-arginine treatment prevented significantly the increase in the lipid peroxidation in diabetic rats, it did not cause any difference in plasma MDA level of control rats (Table 2).

\subsection{Contraction studies}

Cumulative addition of NA $\left(10^{-8}-3 \times 10^{-5} \mathrm{~mol} / \mathrm{L}\right)$ to the isolated organ bath resulted in concentrationdependent contractions in aortae of all groups (Fig. 1). The contractile responses to NA at the concentrations higher than $10^{-7} \mathrm{M}$ in the aortae from untreated diabetic rats were found to be significantly increased compared to untreated control rats (Fig. 1). Similarly, there was also a significant difference in the maximum con-

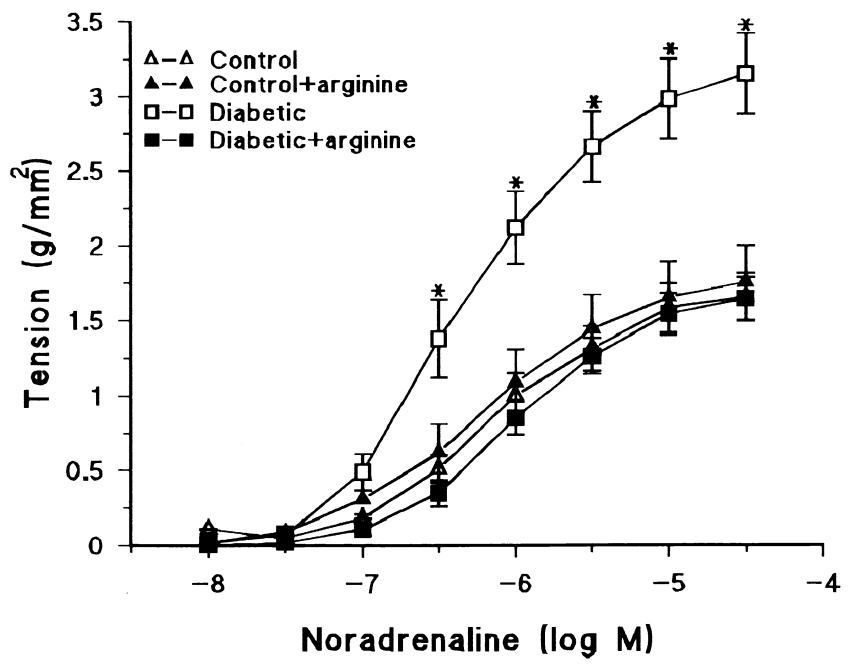

Fig. 1. Cumulative concentration-response curves of noradrenaline in untreated control $(\mathrm{n}=9)$, L-arginine-treated control $(\mathrm{n}=11)$, untreated diabetic $(\mathrm{n}=11)$, and L-arginine-treated diabetic $(\mathrm{n}=11)$ aortic rings. * $\mathrm{p}<0.05$ significantly different from all other groups. traction of the untreated diabetic rats $(3.15 \pm 0.27$ $\left.\mathrm{g} / \mathrm{mm}^{2}\right)$ relative to untreated control rats $(1.65 \pm 0.16$ $\mathrm{g} / \mathrm{mm}^{2}$ ). In contrast, concentration-response curves and also maximum response $\left(1.64 \pm 0.14 \mathrm{~g} / \mathrm{mm}^{2}\right)$ of aortae from L-arginine-treated diabetic rats to NA were very similar to those of aortae from untreated controls (Fig. 1). On the other hand, L-arginine treatment did not alter contractions to NA in control aortae. For example, maximum response to NA was $1.75 \pm 0.25 \mathrm{~g} / \mathrm{mm}^{2}$. With respect to $\mathrm{pD}_{2}$ values of NA, there was no statistical difference among the untreated control, L-arginine treated control, untreated diabetic, or L-argininetreated diabetic groups (Table 3 ).

\subsection{Acetylcholine and SNP relaxation responses}

Addition of $\mathrm{ACh}$ resulted in concentration-dependent relaxations in all aorta rings precontracted with NA. The ACh-induced relaxation was significantly reduced in untreated diabetic rats relative to untreated control rats. The maximum relaxation to $\mathrm{ACh}$ was $89.2 \pm 2.4$ and $63.0 \pm 3.4 \%$ in untreated control and untreated diabetic aortae, respectively. While 12-week L-arginine treatment did not have any effect on AChinduced relaxation in control aortae, it prevented impairment in endothelium-dependent relaxation in diabetic rats (Fig. 2). The maximum relaxations of aortae from L-arginine-treated control and L-arginine-treated diabetic rats were $87.6 \pm 2.9$ and $82.3 \pm 3.7 \%$, respectively. On the other hand, the sensitivity of the aortae from all experimental groups to ACh was similar (Table 3).

The relaxation response and the sensitivity to SNP, the endothelium-independent vasodilator, have been found not to be significantly different in the control, L-arginine-treated control, untreated diabetic, and L-arginine-treated diabetic rats (Fig. 3, Table 3).

\section{Discussion}

The results of the present study demonstrate that aortae from 12-week STZ-diabetic rats are more re- 
Table 3

$\mathrm{pD}_{2}$ values of agonists in aortae from untreated control, L-arginine-treated control, untreated diabetic, and L-arginine-treated diabetic rats

\begin{tabular}{lrlll}
\hline & $\mathrm{n}$ & Noradrenaline & Acetylcholine & $\begin{array}{l}\text { Sodium } \\
\text { nitroprusside }\end{array}$ \\
\hline $\begin{array}{l}\text { Control rats } \\
\quad \text { Untreated }\end{array}$ & 9 & $6.20 \pm 0.09$ & $6.74 \pm 0.18$ & $8.32 \pm 0.20$ \\
$\quad$ L-arginine-treated & 11 & $6.22 \pm 0.16$ & $6.79 \pm 0.17$ & $8.21 \pm 0.16$ \\
Diabetic rats & & & & \\
$\quad$ Untreated & 11 & $6.35 \pm 0.10$ & $6.40 \pm 0.08$ & $8.47 \pm 0.14$ \\
$\quad$ L-arginine-treated & 11 & $6.04 \pm 0.08$ & $6.64 \pm 0.14$ & $8.24 \pm 0.12$ \\
\hline
\end{tabular}

Values are mean \pm SEM.

sponsive to the contractile effects of NA than those from corresponding controls. Similar results showing the increased vascular responsiveness to contractile agents in STZ-diabetic rats have been obtained in most previous studies (Macleod, 1985; Harris and Macleod, 1988; Abebe et al., 1990; Özçelikay et al., 1994). The actual mechanism is not completely understood. Possible mechanisms that could have been involved in the increased vascular smooth muscle responsiveness to NA in diabetic rats are deficient endothelial activity ( $\mathrm{Ka}$ rasu and Altan, 1993; Chang et al., 1993), enhanced phosphoinositide (PI) metabolism (Abebe and Macleod, 1991; Chang et al., 1993), enhanced sensitivity of calcium channels (Abebe et al., 1990, 1994), and increased sensitivity to adrenergic agonists (Macleod and McNeill, 1982). However, our findings show that the increased responsiveness of aortae from untreated diabetic rats to NA did not result from an alteration in the sensitivity of tissue to this agonist because the $\mathrm{pD}_{2}$ value was not significantly different from that of the un-

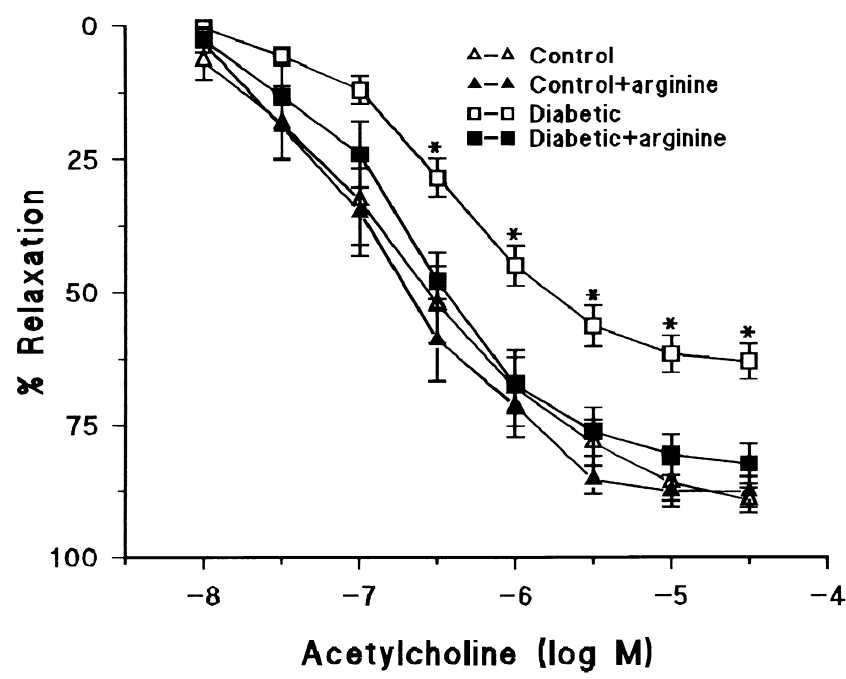

Fig. 2. Cumulative concentration-response curves of acetylcholine in untreated control $(\mathrm{n}=9)$, L-arginine-treated control $(\mathrm{n}=11)$, untreated diabetic $(\mathrm{n}=11)$, and L-arginine-treated diabetic $(\mathrm{n}=11)$ aortic rings precontracted with noradrenaline. $* \mathrm{p}<0.05$ significantly different from all other groups. treated control group. On the other hand, it is well known that endothelium-dependent relaxation response to agonists such as ACh is impaired in diabetic rat aorta (Oyama et al., 1986; Kamata et al., 1989). Similarly, we found that relaxation response to $\mathrm{ACh}$ was decreased in untreated diabetic rats. Therefore, in our study, it seems likely that enhanced contractile response to NA may be associated with the defective endothelial activity. On the other hand, the other possible mechanisms mentioned above should not be ruled out.

In this study, we hypothesized that L-arginine treatment in vivo could prevent the abnormalities in vascular function brought about by diabetes and found that long-term treatment of diabetic rats with the precursor of endothelium-derived relaxing factor/nitric oxide (EDRF/NO) prevented impairment in vascular reactivity caused by experimental diabetes. Our results are consistent with those which show that L-arginine supplementation in vitro (Pieper and Peltier, 1995; Pieper and Dondlinger, 1997; Pieper et al., 1997) or in vivo (Pieper et al., 1996) normalizes endothelium-dependent

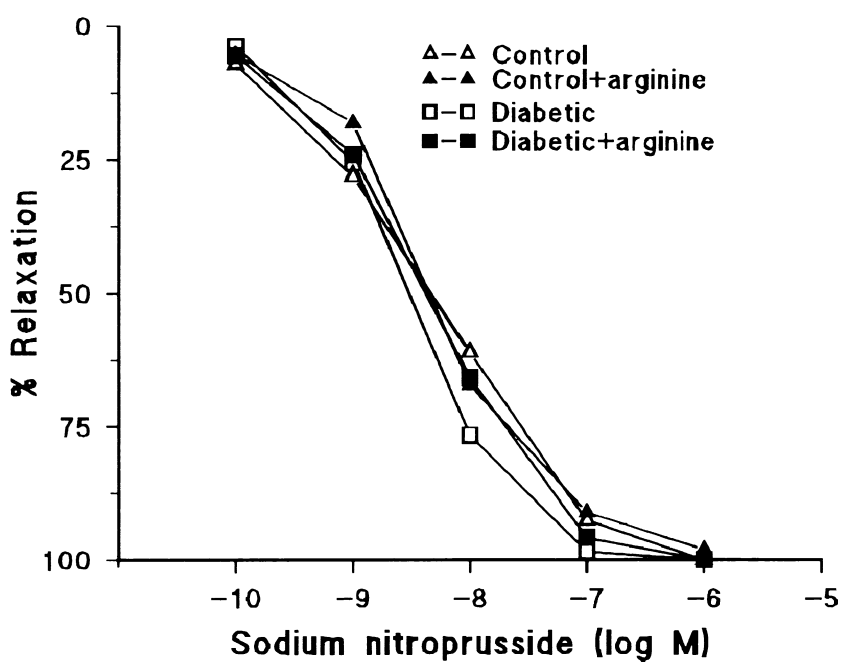

Fig. 3. Cumulative concentration-response curves of sodium nitroprusside in untreated control $(\mathrm{n}=9)$, L-arginine-treated control $(\mathrm{n}=$ $11)$, untreated diabetic $(\mathrm{n}=11)$, and L-arginine-treated diabetic $(\mathrm{n}=$ 11) aortic rings precontracted with noradrenaline. 
relaxation in diabetic rat aorta. In addition, L-arginine also restores both the decrease in endothelium-dependent relaxation and the increase in vasoconstrictor responses in hypercholesterolemic rabbits (Rossitch et al., 1991; Phivthong-ngam et al., 1998) and in DOCA-salt hypertensive rats (Laurant et al., 1995).

In the present study, the beneficial effect of chronic L-arginine treatment on contraction and endotheliumdependent relaxation responses was specific for diabetic aortae because L-arginine treatment did not show any effect in control preparations. Our results also indicate that L-arginine treatment did not increase the sensitivity of vascular smooth muscle of diabetic rats to $\mathrm{NO}$ because relaxation response to SNP was not significantly affected by L-arginine treatment in vivo. These findings are consistent with previous results (Pieper and Peltier, 1995; Pieper and Dondlinger, 1997; Pieper et al., 1997). Although we did not test stereospecificity of the effect of L-arginine, it has been reported that exogenous L-arginine but not $\mathrm{D}$-arginine restores vascular reactivity in diabetic rats (Pieper and Peltier, 1995; Pieper et al., 1997) or in hypercholesterolemic humans (Creager et al., 1992) and rabbits (Rossitch et al., 1991). In the present study, chronic L-arginine treatment did not cause a significant change in plasma insulin, glucose, cholesterol, or triglyceride levels of diabetic rats. These findings show that long-term oral supplementation of L-arginine normalizes the impairment in responsiveness of aorta from diabetic rats without improving metabolic abnormalities. Similarly, L-arginine treatment in vivo did not affect cholesterol or glucose level in hypercholesterolemic rabbits (Böger et al., 1995, 1997) or diabetic rats (Pieper et al., 1996), respectively.

Several other mechanisms could contribute to the preventive effect of L-arginine on the functional abnormalities observed in the diabetic rat aorta. It has been reported that arginine concentrations are decreased in plasma of diabetic patients (Hagenfeldt et al., 1989; Grill et al., 1992) and in plasma and vascular tissue of STZ-diabetic rats (Pieper and Peltier, 1995; Pieper et al., 1996; Pieper and Dondlinger, 1997). Although we have not measured the levels of plasma or tissue arginine, lack of the amino acid levels, as shown in diabetic rats, may cause a decrease in EDRF/NO synthesis and consequently may attenuate endothelium-dependent relaxation. Therefore, in our study, it seems likely that L-arginine treatment may normalize endotheliumdependent relaxation by increasing arginine levels in plasma and vascular tissue. Our results in the present study and previous findings (Pieper and Peltier, 1995; Pieper et al., 1996; Pieper and Dondlinger, 1997; Pieper et al., 1997) confirm the beneficial effect of L-arginine treatment in vitro or in vivo on decreased endotheliumdependent relaxation in response to ACh in aorta from diabetic rats.

In the diabetic state, it is well known that oxidative stress is increased due to excessive production of oxygen-free radicals and decreased antioxidant defense systems (Baynes, 1992; Oberlet, 1988). The oxidative stress may cause development of long-term diabetic complications as a result of glycoxidation and lipid peroxidation (Baynes, 1992, Kennedy and Lyons, 1997). It has been reported that oxidative stress increases DAGPKC activity in hyperglycemic rat aorta (Kunisaki et al., 1994) and results in impaired endothelium-dependent relaxation, increased PI turnover in response to NA, and enhanced contractile responses to $\mathrm{NA}$ and $\mathrm{KCl}$ via alterations in calcium channel activities in STZ-diabetic rat aorta (Chang et al., 1993). Therefore, the oxidative stress in diabetic animals might be responsible for augmented contractility together with deficient endothelial activity (Chang et al., 1993; Tesfamariam, 1994). On the other hand, in several studies, L-arginine in vitro has been shown to improve impairment in endotheliumdependent relaxation evoked by $\mathrm{ACh}$ and to reduce increased lipid peroxidation caused by oxygen-free radicals (Xiong et al., 1994; Wascher et al., 1997) In addition, it has been reported that stimulated superoxide anion production is significantly decreased in hypercholesterolemic rabbits treated with L-arginine in vivo (Böger et al., 1995, 1997). Therefore, a possible mechanism by which L-arginine supplementation improves the vascular reactivity in diabetes may depend on inhibiting the oxidative stress. Indeed, in our study, there is a positive correlation between improved vascular reactivity and normalized lipid peroxidation in L-arginine-treated diabetic rats. Consistent with present findings, studies published recently showed that treatment orally with L-arginine reduced the lipid peroxidation products in patients with diabetes (Lubec et al., 1997a) and in the diabetic mice (Lubec et al., 1995, 1997b). However, whether the lipid peroxidation-lowering effect of L-arginine results from its direct superoxide scavenging properties or increasing $\mathrm{NO}$ synthesis indirectly is controversial because $\mathrm{NO}$ also has antioxidant activity per se in diabetic arteries (Pieper et al., 1992; Chang et al., 1993) On the other hand, advanced stage glycosylation end products (AGEs) such as $\mathrm{N}^{\mathrm{e}}$-Carboxymethyllysine (CML), which may be either a glycoxidation or lipoxidation product (Kennedy and Lyons, 1997), accumulate in diabetes (Schnider and Kohn, 1980; Monnier et al., 1984) and can inactivate NO (Bucala et al., 1991). Because the concentration of CML in glomerular basement membrane collagen has been found to be reduced in the diabetic mice (Weninger et al., 1992; Lubec et al., 1995, 1997b) treated with L-arginine in vivo, and L-arginine can directly inhibit AGEs production in vitro (Servetnick et al., 1996), it is possible that L-arginine improves endothelium-dependent relaxation by preventing NO quenching induced by AGEs. Taken together, these findings suggest that the beneficial effect of L-arginine treatment in diabetic 
rats is attributable to inhibition of the oxidative stress caused by the oxygen-free radicals.

In conclusion, the findings obtained in this study show that chronic treatment of diabetic rats with L-arginine in vivo prevents the changes in the vascular reactivity observed in untreated diabetic rats and that the beneficial effect of L-arginine on vascular reactivity of diabetic rats may result from its lipid peroxidationlowering effect. Therefore, it is suggested that L-arginine treatment in addition to hypoglycemic agents, e.g., insulin and oral antidiabetics, may be applied as a therapeutic regimen for diabetic patients.

\section{Acknowledgments}

We thank Ms. Sahika Güner for skilled assistance. This work was supported by grant No. SBAG-AYD162 from the Scientific and Technical Research Council of Turkey (TÜBİTAK).

\section{References}

Abebe, W., Harris, K.H., Macleod, K.M., 1990. Enhanced contractile responses of arteries from diabetic rats to $\alpha_{1}$-adrenoceptor stimulation in the absence and presence of extracellular calcium. J Cardiovasc Pharmacol 16(2), 239-248.

Abebe, W., Macleod, K.M., 1991. Enhanced arterial contractility to noradrenaline in diabetic rats is associated with increased phosphoinositide metabolism. Can J Physiol Pharmacol 69, 355-361.

Abebe, W., Harris, K.H., Macleod, K.M., 1994. Role of extracellular $\mathrm{Ca}^{2+}$ in the selective enhancement of contractile responses of arteries from diabetic rats to noradrenaline. Can J Physiol Pharmacol 72, 1544-1551.

Baynes, J.W., 1992. Role of oxidative stress in development of complications in diabetes. Diabetes 40, 405-412.

Böger, R.H., Bode-Böger, S.M., Mügge, A., Kienke, S, Brandes, R., Dwenger, A., Frolich, J.C., 1995. Supplementation of hypercholesterolaemic rabbits with L-arginine reduces the vascular release of superoxide anions and restores NO production. Atherosclerosis 117(2), 273-284.

Böger, R.H., Bode-Böger, S.M., Brandes, R.P., Phivthong-ngam, L., Bohme, M., Nafe, R., Mugge, A., Frolich, J.C., 1997. Dietary L-arginine reduces the progression of atherosclerosis in cholesterol-fed rabbits. Comparison with lovastatin. Circulation 96(4), 1282-1290.

Bucala, R., Tracey, K.J., Cerami, A., 1991. Advanced glycosylation products quench nitric oxide and mediate defective endotheliumdependent vasodilatation in experimental diabetes. J Clin Invest 87, 432-438.

Chang, K.C., Chung, S.Y., Chong, W.S., Suh, J.S., Kim, S.H., Noh, H.K., Seong, B.W., Ko, H.J., Chun, K.W., 1993. Possible superoxide radical-induced alteration of vascular reactivity in aortas from streptozotocin-treated rats. J Pharmacol Exp Ther 266, 992-1000.

Christlieb, A.R., Janka, H.U., Kraus, B., Gleason, R.E., IcasasCabral, E.A., Aiello, L.M., Cabral, B.V., Solano, A., 1976. Vascular reactivity to angiotensin II and to norepinephrine in diabetic subjects. Diabetes 25, 268-274.

Cohen, R.A., 1993. Dysfunction of vascular endothelium in diabetes mellitus. Circulation 87, V67-V76.

Creager, M.A, Gallagher, S.J., Girerd, X.J., Coleman, S.M., Dzau, V.J., Cooke, J.P., 1992. L-arginine improves endothelium-dependent vasodilation in hypercholesterolemic humans. J Clin Invest 90, 1248-1253.
Garcia, M.J., McNamara, P.M., Gordon, T., Kannell, W.B., 1974. Morbidity and mortality in diabetics in the Framingham population sixteen-year follow-up study. Diabetes 23, 104-111.

Giuglino, D., Ceriello, A., Paolisso, G., 1995. Diabetes mellitus, hypertension, and cardiovascular disease: Which role for oxidative stress? Metabolism 44, 363-368.

Grill, V., Bjorkman, O., Gutniak, M., Lindqvist, M., 1992. Brain uptake and release of amino acids in nondiabetic and insulin-dependent diabetic subjects: important role of glutamine release for nitrogen balance. Metabolism 41, 28-32.

Hagenfeldt, L., Dahlquist, G., Persson, B., 1989. Plasma amino acids in relation to metabolic control in insulin-dependent diabetic children. Acta Pediatr Scand 794, 278-282.

Harris, K.H., Macleod, K.M., 1988. Influence of the endothelium on contractile responses of arteries from diabetic rats. Eur J Pharmacol 153, 55-64.

Jarrett, R.J., 1989. Cardiovascular disease and hypertension in diabetes mellitus. Diabetes Metab Rev 5, 547-558.

Kamata, K., Miyata, N., Kasuya, Y., 1989. Impairment of endothelium-dependent relaxation and changes on levels of cyclic GMP in aorta from streptozotocin-induced diabetic rats. Br J Pharmacol 97, 614-618.

Karasu, Ç., Altan, V.M., 1993. The role of endothelial cells on the alterations in vascular reactivity induced by insulin-dependent diabetes mellitus: Effects of insulin treatment. Gen Pharmacol 24(3), 743-755.

Kennedy, A.L., Lyons, T.J., 1997. Glycation, oxidation, and lipoxidation in the development of diabetic complications. Metabolism 46, $14-21$.

Kunisaki, M., Bursell, S.E., Umeda, F., Nawata, H., King, G.L., 1994. Normalization of diacylglycerol-protein kinase $\mathrm{C}$ activation by vitamin $\mathrm{E}$ in aorta of diabetic rats and cultured rat smooth muscle cells exposed to elevated glucose levels. Diabetes 43, 1372-1377.

Laurant, P., Demolombe, B., Berthelot, A., 1995. Dietary L-arginine attenuates blood pressure in mineralocorticoid-salt hypertensive rats. Clin Exper Hypertension 17(7), 1009-1024.

Lubec, B., Golej, J., Marx, M., Weninger, M., Hoeger, H., 1995. $\mathrm{L}$-arginine reduces kidney lipid peroxidation, glycoxidation and collagen accumulation in the aging NMRI mouse. Ren Physiol Biochem 18(2), 97-102.

Lubec, B., Hayn, M., Kitzmüller, E., Vierhapper, H., Lubec, G., 1997a. L-arginine reduces lipid peroxidation in patients with diabetes mellitus. Free Radic Biol Med 22, 355-357.

Lubec, B., Aufricht, C., Amann, G., Kitzmüller, E., Höger, H., 1997 b. Arginine reduces kidney collagen accumulation, cross-linking, lipid peroxidation, glycoxidation, kidney weight and albuminuria in the diabetic kk mouse. Nephron 75(2), 213-218.

Macleod, K.M., McNeill, J.H., 1982. Alpha adrenoceptor mediated responses in aorta from three month streptozotocin diabetic rats. Proc West Pharmacol Soc 25, 245-247.

Macleod, K.M., 1985. The effect of insulin treatment on changes in vascular reactivity in chronic, experimental diabetes. Diabetes 34 , $1160-1167$.

McNally, P.G., Watt, P.A.C., Rimmer, T., Burden, A.C., Hearnshaw, J.R., Thurston, H., 1994. Impaired contraction and endotheliumdependent relaxation in isolated resistance vessels from patients with insulin-dependent diabetes mellitus. Clin Sci 87, 31-36.

McVeigh, G.E., Brennan, G.M., Johnston, G.D., McDermott, B.J., McGrath, L.T., Henry, W.R., Andrews, J.W., Hayes, J.R., 1992. Impaired endothelium-dependent and independent vasodilation in patients with type 2 (non-insulin-dependent diabetes mellitus). Diabetologia 35, 771-776.

Monnier, V.M., Kohn, R.R., Cerami, A., 1984. Accelerated agerelated browning of human collagen in diabetes mellitus. Proc Natl Acad Sci USA 81, 583-587.

Oberlet, L.W. 1988. Free radicals and diabetes. Free Radic Biol Med $5,112-124$. 
Oyama, Y., Kawasaki, H., Hattori, Y., Kanno, M., 1986. Attenuation of endothelium-dependent relaxation in aorta from diabetic rats. Eur J Pharmacol 131, 75-78.

Özçelikay, A.T., Pekiner, C., Ari, N., Öztürk, Y., Özüari, A., Altan, V.M., 1994. The effect of vanadyl treatment on vascular responsiveness of streptozotocin-diabetic rats. Diabetologia 37, 572-578.

Phivthong-ngam, L., Bode-Böger, S.M., Böger, R.H., Böhme, M., Brandes, R.P., Mügge, A., Frölich, J., 1998. Dietary L-arginine normalizes endothelin-induced vascular contractions in cholesterol-fed rabbits. J Cardiovasc Pharmacol 32, 300-307.

Pieper, G.M., Mei, D.A., Langenstroer, P., O'Rourke, S.T., 1992. Bioassay of endothelium-derived relaxing factor in diabetic rat aorta. Am J Physiol 263, H676-H680.

Pieper, G.M., Peltier, B.A., 1995. Amelioration by L-arginine of a dysfunctional arginine/nitric oxide pathway in diabetic endothelium. J Cardiovasc Pharmacol 25, 397-403.

Pieper, G.M., Siebeneich, W., Dondlinger, L.A., 1996. Short-term oral administration of L-arginine reverses defective endotheliumdependent relaxation and cGMP generation in diabetes. Eur $\mathrm{J}$ Pharmacol 317, 317-320.

Pieper, G.M., Dondlinger, L.A., 1997. Plasma and vascular tissue arginine are decreased in diabetes: Acute arginine supplementation restores endothelium-dependent relaxation by augmenting cGMP production. J Pharmacol Exp Ther 283, 684-691.

Pieper, G.M., Siebeneich, W., Moore-Hilton, G., Rosa, A.M., 1997. Reversal by L-arginine of a dysfunctional arginine/nitric oxide pathway in the endothelium of the genetic diabetic BB rat. Diabetologia 40, 910-915.
Rossitch, E., Alexander, E., Black, P.M., Cooke, J.P., 1991. L-arginine normalizes endothelial function in cerebral vessels from hypercholesterolemic rabbits. J Clin Invest 87, 1295-1299.

Satoh, K., 1978. Serum lipid peroxide in cerebrovascular disorders determined by a new colorimetric method. Clin Chim Acta 90, 37-43.

Schnider, S.L., Kohn, R.R., 1980. Glucosylation of human collagen in aging and diabetes mellitus. J Clin Invest 66, 1179-1181.

Servetnick, D.A., Bryant, D., Wells-Knecht, K.J., Wiesenfeld, P.L., 1996. L-arginine inhibits in vitro nonenzymatic glycation and advanced glycosylated end product formation of human serum albumin. Amino Acids 11, 69-81.

Tesfamariam, B., 1994. Free radicals in diabetic endothelial cell dysfunction. Free Radic Biol Med 16, 383-391.

Wascher, T.C., Posch, K., Wallner, S., Hermetter, A., Kostner, G.M., Graier, W.F., 1997. Vascular effects of L-arginine: anything beyond a substrate for the NO-synthase? Biochem Biophys Res Commun 234(1), 35-38.

Weidmann, P., Piccoli, C.B., Trost, B.N., 1985. Pressor factors and responsiveness in hypertension accompanying diabetes mellitus. Hypertension 7(Suppl. 2), 33-42.

Weninger, M., Zhou, X.I., Lubec, B., Szalay, S., Höger, H., Lubec, G., 1992. L-arginine reduces glomerular basement membrane collogen $\mathrm{N}$-epsilon-carboxymethyl lysine in the diabetic $\mathrm{db} / \mathrm{db}$ mouse. Nephron 62, 80-83.

Xiong, Y., Li, Y.J., Deng, H.W., 1994. Protection of L-arginine against oxygen free radicals-injured rabbit aortic endothelium. Acta Pharmacol Sin 15, 119-123. 